\title{
AMANAT PADA KUMPULAN CERITA RAKYAT KERINCI SAKUNUNG-SAKUNUNG NINAU DI DESA PULAU TENGAH KABUPATEN KERINCI
}

\author{
Sainil Amral, Nur Azlin² \\ Program Studi Pendidikan Bahasa dan Sastra Indonesia, \\ Fakultas Keguruan dan IlmuPendidikan, Universitas Batanghari. \\ Jambi \\ amralsainil@gmail.com \\ azlinnur186@gmail.com
}

\begin{abstract}
The purpose of this research to describe trusteeship in the folklores of Kerinci Sakunungsakunung ninau in Desa Pulau Tengah Kabupaten Kerinci which consists of two aspects, namely implied trusteeship and express trusteeship. The data in this research is primary data in a form of expressions in the folklores of Kerinci Sakunung-sakunung ninau in Desa Pulau Tengah Kabupaten Kerinci. The source of the data is the folklores of Kerinci Sakunungsakunung ninau in Desa Pulau Tengah Kabupaten Kerinci. This research is qualitative descriptive. Based on the collection of the data, transcribing the data, and analyzing the data, the trusteeship in the folklores of Kerinci Sakunung-sakunung ninau in Desa Pulau Tengah Kabupaten Kerinci can be understood. Moreover the researcher interprets logically and makes conclusions towards findings. Based on data tabulation, two points of view are occured. They are implied trusteeship and express trusteeship. The most dominant type occured is express trusteeship while the least is implied trusteeship. There are 41 expressions found; 20 expressions of implied trusteeship and 21 expressions of express trusteeship. Thus it can be concluded that both implied and express trusteeship occured in the folklores of Kerinci Sakunung-sakunung ninau.
\end{abstract}

Keywords: analysis, trusteeship, Sakunung-sakunung Ninau

${ }^{1}$ Dosen Program Studi Pendidikan Bahasa dan Sastra Indonesia, Fakultas Keguruan dan Ilmu Pendidikan, Universitas Batanghari, Jambi

${ }^{2}$ Mahasiswa Program Studi Pendidikan Bahasa dan Sastra Indonesia, Fakultas Keguruan dan Ilmu Pendidikan, Universitas Batanghari, Jambi

Amanat pada Kumpulan Cerita Rakyat Kerinci Sakunung-Sakunung Ninau di Desa Pulau Tengah Kabupaten Kerinci 


\section{PENDAHULUAN}

Karya sastra merupakan karya yang mampu menjadikan manusia menjadi lebih kreatif. Karya sastra merupakan karya yang menjadikan manusia mampu menuangkan segala cerita di dalam tulisan dengan menggunakan cerita-cerita kehidupan dengan berbagai macam persoalan yang ada. Adanya karya sastra maka manusia dapat menuangkan gagasan-gagasan serta isi hati sehingga mampu menciptakan suatu bentuk karya sastra yang kreatif. Karya sastra merupakan karya berupa sebuah pengalaman dan memunculkan sebuah ide di dalam pemikiran manusia untuk berkarya.

Melalui karya sastra, seorang pengarang menyampaikan pandanganya tentang kehidupan yang ada di sekitarnya. Oleh sebab itu, mengapresiasi karya sastra artinya berusaha menemukan nilai-nilai kehidipan yang tercermin dalam karya sastra. "Banyak nilai-nilai kehidupan yang ditemukan dalam karya sastra tersebut. Sastra sebagai produk budaya manusia berisi nilai-nilai yang hidup dan berlaku dalam masyarakat (Rokhmansyah, 2014:2)."

Karya sastra di Indonesia berkembang sangat pesat karena karya sastra merupakan karya seni yang indah, salah satunya berbentuk cerita rakyat. Setelah selesai membaca cerita rakyat, pembaca mendapat kesan dan pesan tersendiri. Seolah-olah ikut mengalami sendiri pengalaman dalam cerita tersebut. Karya sastra yang diciptakan seorang pengarang tergantung pada tulisanya karena bisa saja karya tersebut memberikan pengaruh yang negatif bagi pembacanya. Karena di dalam karya sastra pasti terdapat bermacam-macam perilaku manusia. Sehingga seorang pengarang bisa membawa pembaca kepada pengaruh yang baik melalui pesan yang disampaikan pengarang melalui karya sastra.

Jenis karya sastra itu berbentuk prosa, puisi, dan drama (Wiyatmi, 2009:20)." Dari ketiga jenis tersebut penelitian ini hanya fokus pada prosa, khusunya cerita rakyat, yang dianggap paling dominan dalam menampilkan unsurunsur sosial. Alasan yang dapat dikemukakan antara lain ialah karena cerita rakyat menampilkan unsur cerita yang paling lengkap, menyajikan masalahmasalah kemasyarakatan yang juga luas, dan bahasa dalam cerita rakyat cenderung merupakan bahasa sehari-hari.

Unsur instrinsik adalah unsur-unsur yang membangun karya sastra itu sendiri. Unsur-unsur inilah yang menyebabkan karya sastra itu hadir sebagai karya sastra. Unsur instrinsik dalam novel merupakan unsur yang secara langsung turut serta membangun cerita (Nurgiyantoro, 2009:23)." Unsur instrinsik terdiri dari tema, latar, alur, amanat, tokoh, penokohan, sudut pandang, dan gaya bahasa.

Menurut Wiyatmi (2009:49),
"Amanat adalah pesan yang ingin disampaikan kepada pembaca atau penonton." Maka amanat dalam cerita rakyat merupakan makna yang tidak semua pembaca dapat menemukanya, karena amanat dalam suatu karya sastra tidak secara jelas disampaikan. Amanat juga diartikan sebagai pesan yang ingin disampaikan oleh pengarang melalui isi cerita yang dikarangnya kepada pembacanya. Amanat yang disampaikan dapat secara langsung (tertulis), melalui dialog antar tokoh dalam cerita atau tidak langsung (tersirat).

Penulis tertarik meneliti amanat karena amanat adalah pesan moral yang ingin disampaikan penulis kepada pembaca berupa nilai-nilai luhur yang dapat dijadikan contoh atau teladan. Amanat pada cerita rakyat ini sangat menarik karena zaman sekarang anak-anak sering mengabaikan moral yang seharusnya ada dalam diri kita masing-masing. Di dalam cerita rakyat ini juga banyak mengajarkan tentang moral yang baik. 
Dalam cerita rakyat inilah khayalan manusia memperoleh kebebasan yang mutlak, karena disitu ditemukan hal-hal yang tidak masuk akal, yang tidak ditemukan dalam kehidupan sehari-hari. Untuk memahami masyarakat pemilik/pendukung cerita, fenomena tersebut tidak kemudian dinilai apakah cerita yang disampaikan nyata atau tidak, tetapi harus dilihat bagaimana mitos itu bekerja dalam masyarakat.

Salah satu daerah di Indonesia yang mempunyai sastra lisan adalah Kabupaten Kerinci. Kerinci merupakan salah satu Kabupaten di Provinsi Jambi dengan daerah pemukiman yang dikelilingi perbukitan dan pegunungan. Kerinci merupakan sebuah daerah yang relatif terisolir dari daerah sekitarnya. Hal ini menyebabkan Kerinci memiliki kebudayaan yang kuat. Hubungan kekerabatan lebih erat dan terikat satu sama lain.

Salah satu sastra lisan yang dimiliki oleh masyarakat Kerinci adalah sakunung. Menurut Ramli (dalam Asparina, 2016:7) "Sakunung berasal dari kata kunung atau konon artinya dongeng". Sejalan dengan pendapat di atas, Asparina (2016:7) menambahkan bahwa "Kata kunung sendiri berasal dari bahasa Kerinci tepatnya di Desa Pulau Tengah yang artinya konon, karena setiap desa yang ada di Kerinci memiliki bahasa yang berbeda-beda". Demikianlah sakunung itu adalah dongeng, cerita rakyat, atau folklor yang dikarang oleh sastrawan nenek moyang zaman dahulu sebagai hasil imajinasi. Dalam sakunung tokoh-tokoh yang ditampilkan umumnya manusia dari kalangan bawah ataupun tokoh binatang. Sakunung menceritakan bagaimanakah tokoh-tokoh kecil itu berubah nasib hidupnya menjadi orang yang beruntung didalamnya, digambarkan pula peran tokoh yang patut ditiru, tokoh yang tingkah lakunya buruk untuk ditiru disamping tokoh- tokoh jenaka yang menggelikan atau menggembirakan.

Hampir semua cerita yang terdapat di dalam sakunung berbahasa Indonesia, namun judul cerita dalam sakunung tetap dipertahan dalam bahasa daerah. Itu agar orang yang membaca sakunung tersebut tau bahwa dongeng yang terdapat di desa Pulau Tengah adalah budaya Kerinci. Dalam hal ini, penulis tertarik meneliti sakunung karena selain penulis sendiri berasal dari daerah yang melahirkan sakunung, penulis juga ingin mengenalkan sastra lisan yang ada di Pulau Tengah Kabupaten Kerinci ini agar lebih dikenal oleh masyarakat luas, dan juga penelitian ini memudahkan penulis untuk mendapatkan data.

Fokus penelitian ini ialah membahas amanat. Amanat terbagi atas amanat tersirat dan amanat tersurat. Dengan demikian penulis meneliti tentang amanat tersirat dan amanat tersurat pada kumpulan cerita rakyat Kerinci Sakunung-sakunung Ninau di Desa Pulau Tengah Kabupaten Kerinci. Kumpulan Sakunung-sakunung Ninau di Desa Pulau Tengah Kabupaten Kerinci ini terdiri dari 15 judul sakunung yang diteliti.

Adapun pertanyaan dalam penelitian ini adalah sebagai berikut. (1) Bagaimanakah amanat tersirat pada kumpulan cerita rakyat Kerinci Sakunungsakunung Ninau di Desa Pulau Tengah Kabupaten Keinci? (2) Bagaimanakah amanat tersurat pada kumpulan cerita rakyat Kerinci Sakunung-sakunung Ninau di Desa Pulau Tengah Kabupaten Keinci?

Tujuan penelitian ini adalah sebagai berikut. 1) Mendeskripsikan amanat tersirat pada kumpulan cerita rakyat Kerinci Sakunung-sakunung Ninau di Desa Pulau Tengah Kabupaten Kerinci. (2) Mendeskripsikan amanat tersurat pada kumpulan cerita rakyat Kerinci Sakunungsakunung Ninau di Desa Pulau Tengah Kabupaten Kerinci. 
Sastra adalah tulisan atau bahasa yang indah yakni hasil ciptaan bahasa dan perwujudan getaran jiwa dalam bentuk lisan. Indah adalah sesuatu yang menimbulkan orang yang melihat dan mendengarkan dapat bergetar jiwanya sehingga melahirkan keharuan, kemesraan, kebencian, kecemasan, dendam, dan seterusnya (Wicaksono, 2017:7). Selanjutnya pengertian sastra menurut Sumardjo (dalam Rokhmansyah, 2014:2) "Sastra adalah ungkapan pribadi manusia yang berupa pengalaman, pemikiran, perasaan, ide, dan semangat keyakinan dalam suatu gambaran konkret yang membangkitkan pesona dengan bahasa".

Kata sastra berasal dari bahasa Sansekerta yaitu berasal dari bahasa sas yang dalam kata kerja turunan berarti "mengarahkan, mengajar, buku petunjuk atau instruksi' sedangkan akhiran -tra menunjukkan "alat, sarana". Kata sastra dapat diartikan sebagai alat untuk mengajar, buku petunjuk, buku instruksi, atau pengajaran yang baik dan indah, Teeuw (dalam Rokhmansyah, 2014:1) Hakikat sastra adalah segala sesuatu yang berada pada sesuatu yang paling dasar dari sebuah konstruksi pemikiran. Melalui hakikat, sastra dapat dibentuk menjadi sebuah karya yang baik. Konsep inilah yang digunakan sebagai dasar pemahaman hakikat sastra dalam penelitian ini.

Rokhmansyah (2014:2) mengatakan bahwa "Karya sastra adalah inspirasi kehidupan yang dimaterikan (diwujudkan) dalam sebuah bentuk keindahan." Karya sastra merupakan karya yang dihasilkan dari fenomena kehidupan yang dijadikan sebagai suatu karya yang indah. Karya sastra tercipta dengan baik, imajinatif, akan tetapi dalam penyusunanya tentu memiliki aturan.

Karya sastra disusun oleh pengarang dengan berbagai cara agar mampu menjadi suatu karya sastra yang baik. "Karya sastra dipandang sebagai sarana untuk menyampaikan tujuan tertentu, karya sastra secara tidak langsung maupun sadar, pengarang telah memberikan ajaran hidup terhadap banyak orang melalui karya sastra yang mengandung nilai-nilai ajaran tersebut (Wiyatmi, 2009:18)."

Karya sastra memiliki beberapa bagian-bagian di dalamnya, secara garis besar karya sastra memiliki beberapa jenis. "Jenis karya sastra adalah suatu hasil klasifikasi terhadap bentuk dan isi karya sastra yang terdapat dalam realitas (Wiyatmi, 2009:20)." Selain pengertian yang telah dipaparkan di atas, adapun jenisjenis karya sastra adalah puisi, prosa, dan drama.

Sastra lisan merupakan suatu dunia yang lapang, dunia yang melibatkan banyak orang, dunia untuk banyak orang dalam arti kata sebenarnya. Ketika sastra lisan tersaji, penampil dan khalayak duduk bersama di satu tempat pada satu waktu yang sama. Penampil mengubah, mendendangkan, dan menyuguhkan untuk khalayak yang duduk bersama. Khalayak yang datang ke tempat pertunjukan umumnya bertujuan untuk menikmati pertunjukan sebagai hiburan, (Amir, 2013:75).

Sastra tulisan (sastra tertulis) yaitu sastra yang menggunakan media tulisan atau literal. Menurut Wiyatmi (2009:17), awal sejarah sastra tulis melayu dapat dirunut sejak abad ke-7 M. Berdasarkan penemuan prasasti bertuliskan huruf Pallawa (683) Talang Tuo (684) Kota Kapur (686) dan Karang Berahi (686). Meskipun tulisan pada prasasti-prasasti ini masih pendek-pendek, tetapi prasasti-prasasti yang merupakan benda peninggalan sejarah dapat disebut cikal bakal dihasilkannya tradisi penulisan atau bahasa yang dituangkan dalam bentuk tulisan.

Amanat merupakan pesan dalam suatu karya sastra. "Amanat adalah segala sesuatu yang ingin disampaikan pengarang, yang ingin ditanyakan secara tidak langsung 
ke dalam benak para penonton (Rokhmansyah, 2014:42).” Selanjutnya menurut Wiyatmi (2009:49) "Amanat adalah pesan yang ingin disampaikan kepada pembaca atau penonton." Maka amanat dalam cerita rakyat merupakan makna yang tidak semua penonton dapat menemukanya, karena amanat dalam suatu karya sastra tidak secara jelas disampaikan.

Hakikat amanat merupakan pesan pengarang yang disampaikan melalui tulisannya baik berupa novel ataupun cerbung. Pembaca diharapkan cukup teliti untuk mengungkap apa yang tersirat dalam karya sastra tersebut. Amanat biasanya memberikan manfaat dalam kehidupan secara praktis. Amanat dibuat oleh pengarang dapat disebut juga pesan terselubung yang disampaikan oleh pengarang (Rokhmansyah, 2014:33).

Nurgiyantoro (dalam Amril, 2017:20) menjelaskan "Jenis amanat atau pesan moral dapat mencakup seluruh persoalan hidup dan kehidupan manusia, hal tersebut dapat dibedakan sebagai berikut: (1) hubungan manusia dengan diri sendiri; (2) hubungan manusia dengan manusia lain dalam lingkungan sosial dan lingkungan alam; dan (3) hubungan manusia dengan Tuhannya.

\section{METODE PENELITIAN}

Dalam penelitian sastra terdapat beberapa sudut pandang atau pendekatan dalam menganalisisnya. Jenis penelitian sastra yang dilakukan seorang peneliti tergantung dari sudut pandang mana yang dipakai penelitinya (Rahima, 2017:1). Jenis penelitian ini adalah penelitian deskriptif kualitatif. Dasar pendekatan yang peneliti gunakan bersifat kualitatif dengan metode deskriptif. Tekait hal ini, Siswantoro (2010:55) mengungkapkan bahwa jenis penelitian menggambarkan bagaimana cara yang digunakan seorang peneliti di dalam usaha memecahkan masalah yang teliti (Siswantoro, 2010:55)." Jenis penelitian merupakan arahan peneliti sehingga dapat mencapai tujuan penelitian. Peneliti dapat memilih jenis penelitian yang sesuai dengan tujuan. Dalam keberhasilan penelitian tentu sangat dipengaruhi oleh jenis penelitian yang digunakan.

Tempat penelitian merupakan lokasi dalam melakukan penelitian. Tempat penelitian ini dilaksanakan di Jambi.

Data primer merupakan data utama yang sangat penting dalam sebuah penelitian. "Data primer adalah data utama yaitu data yang diseleksi atau diperoleh langsung dari sumbernya tanpa perantara (Siswantoro, 2010:70)." Data primer penelitian ini yaitu kalimat atau kutipankutipan yang berisi amanat baik amanat tersirat maupun amanat tersurat yang terdapat dalam kumpulan cerita rakyat Kerinci Sakunung-sakunung Ninau di Desa Pulau Tengah Kabupaten Kerinci, sedangkan data sekunder merupakan data yang diperoleh secara tidak langsung atau melalui perantara. "Data skunder adalah data yang diperoleh secara tidak langsung atau melalui perantara tetapi tetap bersandar kepada kategori atau parameter yang menjadi rujukan (Siswantoro, 2010:71). Data sekunder dalam penelitian ini merupakan semua buku yang berkaitan langsung dengan analisis amanat pada kumpulan cerita rakyat Kerinci Sakunungsakunung Ninau di Desa Pulau Tengah Kabupaten Kerinci.

Sumber data merupakan data yang diperoleh dari sumber yang akan diteliti. "Sumber data terkait dengan subjek penelitian dari mana data diperoleh (Siswantoro, 2010:72)". Sumber data dalam penelitian ini adalah kumpulan cerita rakyat Kerinci Sakunung-sakunung Ninau di Desa Pulau Tengah Kabupaten Kerinci.

Teknik pengumpulan data dalam penelitian ini menggunakan teknik dokumentasi, yang memfokuskan pada tujuan untuk mendekripsikan analisis 
amanat kumpulan Sakunung-sakunung Ninau di Desa Pulau Tengah Kabupaten Kerinci. Dengan demikian tujuan dari peneliti ini dapat terarah.

Metode simak adalah metode yang digunakan untuk memperoleh data dengan melakukan penyimakan terhadap pengguna bahasa. Metode ini memiliki teknik lanjutan, yaitu teknik simak bebas libat cakap, dan teknik catat (Mahsun, 2007: 242).

Dalam Pengumpulan data, penulis melampirkan langkah-langkah pengumpulan data yang berhubungan dengan amanat pada kumpulan cerita rakyat sakunung di Desa Pulau Tengah Kabupaten Kerinci. Teknik pengumpulan data dalam penelitian ini dilakukan dengan langkah-langkah sebagai berikut (Sukardi, 2009:33):

1. Peneliti membaca keseluruhan naskah cerita rakyat Kerinci Sakunungsakunung Ninau dengan seksama dan hati-hati.

2. Peneliti memahami literatur-literatur yang berkaitan dengan amanat maupun teori lainnya yang berhubungan dengan penelitian ini.

3. Peneliti menandai teks dalam naskah sakunung yang berhubungan dengan amanat.

4. Peneliti mengidentifikasikan data yang menggambarkan amanat pada kumpulan cerita rakyat Kerinci Sakunungsakunung Ninau di Desa Pulau Tengah Kabupaten Kerinci.

5. Peneliti mengelompokkan data yang berhubungan dengan amanat pada kumpulan cerita rakyat Kerinci Sakunung-sakunung Ninau di Desa Pulau Tengah Kabupaten Kerinci.

"Teknik analisis data dilakukan dengan memaparkan dalam bentuk deskriptif terhadap masing-masing data secara fungsional dan rasional (Siswantoro, 2010:81)." Teknik analisis data dengan pemaparan dalam bentuk kata-kata, kalimat, paragraf yang berhubungan dengan aspek amanat padakumpulan Sakunung-sakunung Ninau di Desa Pulau Tengah Kabupaten Kerinci.

Kegiatan analisis data dilakukan dengan langkah-langkah sebagai berikut (Sugiyono, 2016:7) :

1. Mengumpulkan data dan kemudian dikelompokkan sesuai dengan permasalahan dalam penelitian ini.

2. Membuat tabel tabulasi data yang telah di kelompokkan berdasarkan aspekaspek yang diteliti, selanjutnya data di masukkan ke dalam tabel tabulasi data.

3. Data yang sudah dianalisis sesuai dengan teori yang berkaitan dengan malah penelitian selanjutnya penulis deskripsikan.

4. Langkah berikutnya penulis melakukan keabhasan data dengan cara memasukkan data yang penulis dapat ke dalam tabel tabulasi data. Keabhasan data ada tiga, yaitu pertama mengabsahkan data dengan teori, kedua mengabsahkan data dengan metode, dan ketiga mengabsahkan data dengan pakar atau pembimbing.

5. Langkah terakhir, merumuskan kesimpulan.

\section{HASIL DAN PEMBAHASAN}

Berdasarkan penelitian yang telah dilakukan, ditemukan beberapa aspek yang berkaitan dengan amanat tersirat dan tersurat dalam cerita rakyat Kerinci Sakunungsakunung Ninau di Desa Pulau Tengah Kabupaten Kerinci, sebanyak 41 kutipan, dengan rincian sebagai berikut.

1. Aspek tersirat sebanyak 20 kutipan

Amanat tersirat terdapat pada 10 judul sakunung dari 15 judul sakunung, diantaranya: (1) Taroh, terdapat 1 kutipan, (2) Lukoh Incauk (Tinggi Kaau Batiu), terdapat 2 kutipan, (3) Puyah Ambea, terdapat 2 kutipan, (4) Tupo Sakantai dengan Mujeuk, terdapat 1 kutipan, (5) Pijah Gajah, terdapat 3 kutipan, (6) Antu Guriu, 
terdapat 1 kutipan, (7) Antau Rakikak-rakiki, terdapat 4 kutipan, (8) Ayo Dinga Muso, terdapat 2 kutipan, (9) Silah, terdapat 2 kutipan, dan (10) Mampatau Nangaih, terdapat 2 kutipan.Dari 20 kutipan amanat tersirat, yang paling dominan terdapat pada sakunung Antau Rakikak-rakiki yaitu terdapat 4 kutipan yang mengacu pada amanat pentingnya hidup rukun dengan saudara kandung. Dan yang paling sedikit ditemukan terdapat pada 3 judul sakunung yaitu; (1) Taroh terdapat 1 kutipan yang mengacu pada amanat larangan mencuri, (2) Tupo Sakantai dengan Mujeuk terdapat 1 kutipan yang mengacu pada amanat pentingnya menolong orang yang butuh pertolongan, dan (3) Antu Guriu, terdapat 1 kutipan yang mengacu pada amanat pentingnya belajar mengaji sejak usia dini.

2. Aspek tersurat sebanyak 21 kutipan

Amanat tersurat terdapat pada 8 judul sakunung dari 15 sakunung, diantaranya: (1) Puti Lumo dengan Puti Caketung, terdapat 9 kutipan, (2) Taroh, terdapat kutipan, (3) Lukoh Incauk (Tinggi Kaau Batui), terdapat 2 kutipan, (4) Baeuk Babideuk Ka'ok, terdapat 3 kutipan, (5) Tupo Sakantai dengan Mujeuk, terdapat 2 kutipan, (6) Uheu Kinto Wa Puyah, terdapat 1 kutipan, (7) Tinggoa Sarabbab Kaau, terdapat 2 kutipan, dan (8) Ayah Ande Ngong, terdapat 1 kutipan. Dari 21 kutipan amanat tersurat, yang paling dominan terdapat pada sakunung Puti Lumo dengan Puti Caketung yaitu sebanyak 9 kutipan. Kutipaan tersebut mengacu pada amanat Puti Lumo yang miskin dan yatim piatu, tapi memiliki sifat yang baik hati, rajin, dan mandiri, sedangkan Puti Caketung orang kaya yang sombong, pemalas, dan tidak mau membantu orang tua. Kemudian amanat yang paling sedikit terdapat pada 3 judul sakunung yaitu; (1) Taroh terdapat 1 kutipan yang mengacu pada amanat larangan mencuri, (2) Uheu Kinto Wa Puyah terdapat 1 kutipan yang mengacu pada amanat pentingnya menjaga tali persaudaraan, dan (3) Ayah Ande Ngong terdapat 1 kutipan yang mengacu pada amanat pentingnya menghargai makanan yang telah dibuat.

Berdasarkan penjelasan di atasdiketahui jumlah semua aspek dalam kutipan adalah 41 kutipan. Hasil penelitian yang dilakukan untuk menemukan dan mendeskripsikan unsur amanat pada cerita rakyat Kerinci Sakunung-sakunung Ninau di Desa Pulau Tengah Kabupaten Kerinci yang disajikan dalam bentuk deskripsi dan diperjelas dengan menggunakan tabel. Tabel tersebut berisi temuan amanat dan deskripsi amanat.

Dari hasil penafsiran terhadap kumpulan cerita rakyat Kerinci Sakunungsakunung Ninau di Desa Pulau Tengah Kabupaten Kerinci ditemukan beberapa jenis pesan atau amanat yang ingin disampaikan empunya cerita kepada pembaca agar diikuti. Secara garis besar, pesan atau amanat tersebut merupakan himbauan atau ajakan dan larangan yang mengacu kepada hal positif yang menyangkut mengenai persoalan hidup dan kehidupan manusia.

Untuk lebih memperjelas deskripsi amanat yang terdapat dalam kumpulan cerita rakyat Kerinci Sakunung-sakunung Ninau di Desa Pulau Tengah Kabupaten Kerinci, disajikan pada tabel berikut. 


\section{Tabel 1. Pesan/Amanat pada Kumpulan Cerita Rakyat Kerinci Sakunung- sakunung Ninau di Desa Pulau Tengah Kabupaten Kerinci}

\begin{tabular}{clccc}
\hline \multirow{2}{*}{ No. } & \multicolumn{1}{c}{ Judul Sakunung } & \multirow{2}{*}{ Kode } & \multicolumn{2}{c}{ Amanat } \\
\cline { 3 - 5 } & & & Tersirat & Tersurat \\
\hline 1. & Puti Lumo dengan Puti caketung & PLPC & - & 9 \\
\hline 2. & Taroh & TRH & 2 & 1 \\
\hline 3. & Lukoh Incauk (Tinggi kau Batui) & LI & - & 3 \\
\hline 4. & Baeuk Babideuk Ka'ok & BBK & 2 & - \\
\hline 5. & Puyah Ambea & PA & 1 & 2 \\
\hline 6. & Tupo Sakantai dengan Mujeuk & TSM & - & 1 \\
\hline 7. & Uheu Kinto Wa Puyah & UKWP & - & 2 \\
\hline 8. & Tinggoa Sarabbab Kaau & TSK & 3 & - \\
\hline 9. & Pijah Gajah & PG & 1 & - \\
\hline 10. & Antu Guriu & AG & 4 & - \\
\hline 11. & Antau Rakikak-Rakiki & ARR & 2 & - \\
\hline 12. & Ayo Dinga Muso & ADM & 2 & - \\
\hline 13. & Silah & SLH & 2 & - \\
\hline 14. & Mampatau Nangaih & MN & - & 1 \\
\hline 15. & Ayah Ande Ngong & AAN & 20 & 21 \\
\hline & Jumlah & & 21 \\
\hline
\end{tabular}

Dari 20 kutipan amanat tersirat, yang paling dominan terdapat pada sakunung Antau Rakikak-rakiki yaitu terdapat 4 kutipan yang mengacu pada kisah seorang pemuda yang dikenal sebagai hantu tertawa. Kemudian yang paling sedikit d terdapat pada 3 judul sakunung yaitu; (1) Taroh terdapat 1 kutipan yang mengacu pada kisah seorang pencuri, (2) Tupo Sakantai dengan Mujeuk terdapat 1 kutipan yang mengacu pada kisah persahaban tupai dan ikan mujair, dan (3) Antu Guriu terdapat 1 kutipan yang mengacu pada kisah sekelompok murid yang ingin mengaji.

Dari 21 kutipan amanat tersurat, yang paling dominan terdapat pada sakunung Puti Lumo dengan Puti Caketung yaitu terdapat sebanyak 9 kutipan yang mengacu pada kisah Puti Lumo yang baik hati dan Puti Caketung yang sombong. kemudian yang paling sedikit ditemukan terdapat pada 3 judul sakunung yaitu; (1) Taroh terdapat 1 kutipan yang mengacu pada kisah para harimau yang takut pada
Taroh; (2) Uheu Kinto Wa Puyah terdapat 1 kutipan yang mengacu pada kisah burung kemiri yang tidak bisa hidup di sarang burung puyuh, dan burung puyuh tidak bisa hidup di sarang burung kemiri; dan (3) Ayah Ande Ngong terdapat 1 kutipan yang mengacu pada kisah Ayah Ande yang meremehkan masakan istrinya.

\section{SIMPULAN}

Kesimpulan tentang amanat dalam kumpulan cerita rakyat Kerinci Sakunungsakunung Ninau di Desa Pulau Tengah Kabupaten Kerinci. Amanat tersebut terdapat dua aspek yaitu amanat tersirat dan amanat tersurat.

Amanat tersirat adalah sesuatu yang ingin disampaikan pengarang, yang dinyatakan secara tidak langsung atau implisit. Amanat tersirat dalam kumpulan cerita rakyat Kerinci Sakunung-sakunung Ninau di Desa Pulau Tengah Kabupaten Kerinci ditemukan sebanyak 20 kutipan, pada 10 judul sakunung dari total 15 judul sakunung. Kutipan tersebut diantaranya 
sebagai berikut: (1) Taroh, terdapat 1 kutipan; (2) Lukoh Incauk (Tinggi Kaau Batiu) terdapat 2 kutipan; (3) Puyah Ambea, terdapat 2 kutipan; (4) Tupo Sakantai dengan Mujeuk terdapat 1 kutipan, (5) Pijah Gajah terdapat 3 kutipan; (6) Antu Guriu, terdapat 1 kutipan, (7) Antau Rakikak-rakiki terdapat 4 kutipan, (8) Ayo dinga Muso terdapat 2 kutipan, (9) Silah, terdapat 2 kutipan, dan (10) Mampatau Nangaih, terdapat 2 kutipan. Dari 20 kutipan amanat tersirat, yang paling dominan terdapat pada sakunung Antau Rakikak-rakiki yaitu sebanyak 4 kutipan yang mengacu pada kisah seorang pemuda yang dikenal sebagai hantu tertawa. Kemudian yang paling sedikit ditemukan sebanyak 3 judul sakunung yaitu; (1) Taroh terdapat 1 kutipan; (2) Tupo Sakantai dengan Mujeuk terdapat 1 kutipan, dan (3) Antu Guriu terdapat 1 kutipan.

Amanat tersurat adalah amanat yang tertulis jelas pada cerita secara langsung atau eksplisit. Amanat tersirat dalam kumpulan cerita rakyat Kerinci Sakunung-sakunung Ninau di Desa Pulau Tengah Kabupaten Kerinci ditemukan sedikitnya 21 kutipan. Amanat tersurat terdapat pada 8 judul sakunung dari 15 sakunung rakyat, diantaranya: (1) Puti Lumo dengan Puti Caketung, terdapat 9 kutipan, (2) Taroh, terdapat kutipan; (3) Lukoh Incauk (Tinggi Kaau Batui), terdapat 2 kutipan; (4) Baeuk Babideuk Ka'ok, terdapat 3 kutipan; (5) Tupo Sakantai dengan Mujeuk, terdapat 2 kutipan; (6) Uheu Kinto Wa Puyah, terdapat 1 kutipan; (7) Tinggoa Sarabbab Kaau, terdapat 2 kutipan; dan (8) Ayah Ande Ngong, terdapat 1 kutipan. Dari 21 kutipan amanat tersurat, yang paling dominan terdapat pada sakunung Puti Lumo dengan Puti Caketung sebanyak 9 kutipan. Dan yang paling sedikit ditemukan terdapat pada 3 judul sakunung yaitu; (1) Taroh terdapat 1 kutipan; (2) Uheu Kinto Wa Puyah terdapat 1 kutipan; dan (3) Ayah Ande Ngong terdapat 1 kutipan.
Dari penjelasan di atas, maka dapat disimpilkan bahwa dari 15 judul sakunung yang menjadi subjek dalam penelitian ini amanat yang paling dominan ditemukan adalah amanat tersurat berjumlah 21 kutipan, sedangkan amanat yang paling sedikit ditemukan adalah amanat tersirat yang berjumlah 20 kutipan. Amanat baik yang terdapat dalam cerita ini baik tersirat maupun tersurat dapat dijadikan contoh dan teladan bagi pembaca. Sedangkan amanat buruk dalam cerita ini baik tersirat maupun tersurat tidak dapat dijadikan contoh atau teladan. Sebaiknya pembaca dapat membedakan amanat baik maupun buruk dalam cerita ini agar berdampak baik bagi pembaca.

\section{SARAN}

Berdasarkan kesimpulan di atas, maka beberapa saran yang dapat disampaikan sebagai berikut.

1. Kepada mahasiswa program studi pendidikan bahasa dan sastra Indonesia. Para mahasiswa hendaknya lebih mencintai karya sastra, dan mencintai karya bangsa. Karya sastra tidak hanya menghibur, tetapi juga memberi pengetahuan.

2. Kepada guru bahasa dan sastra Indonesia. Guru hendaknya dapat memaksimalkan penggunaan bahan pengajaran sastra, dalam hal ini adalah cerita rakyat. kumpulan cerita rakyat Kerinci Sakunung-sakunung Ninau di Desa Pulau Tengah Kabupaten Kerinci memiliki banyak manfaat terutama pada amanat. Setiap membaca carita kita pasti dapat menyimpulkan amanat apa yang terdapat pada cerita tersebut.

3. Kepada peneliti lain diharapkan dapat menganalisis cerita rakyat atau melakukan kajian-kajian pada cerita rakyat yang bermanfaat bagi peradaban atau kebudayaan manusia. 


\section{DAFTAR PUSTAKA}

Amir, A. (2013). Sastra Lisan Indonesia. Yogyakarta: Gramedia.

Amril, Zahra Nur Oktavia. (2017). Tema dan Amanat dalam Novel "Memang Jodoh" Karya Marah Rusli serta Pemanfaatannya sebagai Alternatif Materi Pembelajaran Apresiasi Sastra di SMA. Universitas Jember. (digital repository Universitas Jember diakses 2 Agustus 2019).

Asparina, Meri. (2016). Nilai-nilai Budaya dalam Sakunung Kerinci. Skripsi. Jambi: Universitas Jambi.

Mahsun. (2007). Metode Penelitian Bahasa. Jakarta: PT Raja Grafindo Persada.

Nurgiantoro, Burhan. (2009). Teori Pengkajian Fiksi. Yogyakarta: Gajah Mada.

Rahima, A. (2017). Literature Reception (a Conceptual Overview). Jurnal Ilmiah Dikdaya, 6(1), 1-16.

Rokhmansyah, Alfian. (2014). Studi dan Pengkajian Sastra. Yogyakarta: PT Remaja Rosdakarya.

Siswantoro. (2010). Metode Penelitian Sastra. Yogyakarta: Pustaka Belajar.

Sugiyono. (2016). Metode Penelitian Kuantitatif dan Kualitatif. Bandung: Alfabeta.

Sukardi. (2009). Metode Penelitian Pendidikan (Kompetensi dan Praktiknya). Jakarta: Bumi Aksara.

Wicaksono, Andri. (2017). Pengkajian Prosa Fiksi. Yogyakarta: Garudhawaca.

Wiyatmi. (2009). Pengantar Kajian Sastra. Yogyakarta: Pustaka Book Publishing. 